\title{
Theodoros Theodoridis: Spinal injection technique
}

\section{Second Edition, Thieme Verlag, New York, Stuttgart, Delhi, Rio de Janeiro, 2019, 308 pp.; 503 figs.; Hardcover, EUR (D) 174,99 EUR (A) 179,90 CHF 201,00, ISBN: 978-3-13-241447-1}

\author{
Alain G. Graftiaux ${ }^{1}$ - Pierre H. Kehr ${ }^{1}$ \\ Received: 10 August 2019 / Accepted: 14 September 2019 / Published online: 30 September 2019 \\ (c) Springer-Verlag France SAS, part of Springer Nature 2019
}

Between medical treatment and surgical treatment are a place for infiltration. Although, as the authors point out, evidence has not been proven, the fact remains that infiltrations render many services both therapeutic and of differential diagnosis.

This book is therefore intended to popularize this treatment. The second edition is therefore an update with the addition of new techniques.

The first part deals with the basics of the therapeutic and diagnostic management of pain that is causal or symptomatic.

The second part is a richly illustrated atlas showing step by step the various cervical, thoracic and lumbar infiltrations. Anatomy, contraindications and patient information are useful additions to the practical descriptions. Complications and their treatments are also described.
It is therefore a book and a very complete e-book that will interest both doctors and surgeons beginner and confirmed as well as orthopedists and neurosurgeons or more widely all the surgeons of the column who want to know more or to learn about infiltration.

\section{Compliance with ethical standards}

Conflict of interest The authors declare that they have no competing interest.

Publisher's Note Springer Nature remains neutral with regard to jurisdictional claims in published maps and institutional affiliations.
Pierre H. Kehr

pierre.kehr@gmail.com

1 Strasbourg, France 